\title{
MAIS REALISTAS DO QUE O REI: O NORMATIVISMO IRREAL DOS LIVROS DIDÁTICOS DE PORTUGUÊS
}

Marcos Bagno

\begin{abstract}
RESUMO
Apesar dos muitos avanços no ensino de língua materna no Brasil nos últimos anos, o tratamento dado pelos livros didáticos de português aos conhecimentos linguísticos ainda se vincula a uma pedagogia de transmissão acrítica das prescriçóes normativas tradicionais. A partir de uma análise de 24 coleçóes desses livros, evidencia-se o hipernormativismo dessas obras, mais estrito do que o da própria tradição normativa.
\end{abstract}

PALAVRAS-CHAVES: ensino de português; livros didáticos; normativismo.

\section{Introdução}

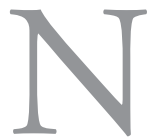

To contexto avaliativo do PNLD (Programa Nacional do Livro Didático), promovido pelo Ministério da Educação para aquisição de material didático a ser distribuído às escolas públicas, os conteúdos curriculares da área de Língua Portuguesa têm sido organizados em quatro grandes eixos: (1) leitura, (2) produção de textos, (3) linguagem oral e (4) conhecimentos linguísticos. A articulação desses quatro eixos orienta todo o processo de avaliação pedagógica das coleçôes didáticas, empreendido por um grupo considerável de especialistas vinculados a instituiçôes de ensino superior das diferentes regiôes brasileiras. Em sua edição 2008, por exemplo, que será objeto deste artigo, o PNLD de Língua Portuguesa contou com uma equipe de 84 profissionais, entre comissão técnica, coordenadores 
nacionais e regionais, pareceristas e leitores críticos, sem contar as muitas pessoas, no próprio Ministério da Educação e também no Ceale (Centro de Alfabetização, Leitura e Escrita da UFMG, responsável pela coordenação institucional do processo), que trabalharam no suporte técnico e logístico dessa operação extremamente complexa e trabalhosa. O inegável impacto positivo do PNLD sobre os rumos da educação brasileira nos últimos tempos justifica plenamente tamanho esforço e investimento de tempo, competências e verbas públicas.

O eixo denominado conhecimentos linguisticos engloba todas as exposiçóes teóricas e propostas de atividades práticas que, nos livros didáticos (doravante $\mathrm{LD}$ ), procuram abordar os conteúdos curriculares relativos ao discurso, aos gêneros textuais, à organização textual è descrição gramatical. Em declarada ruptura com as práticas tradicionais do ensino de língua, no processo avaliativo do PNLD não se considera o "ensino da gramática" como o único (nem como o principal) objeto e objetivo da pedagogia de língua materna. Ao contrário dessas práticas tradicionais, que se limita(va)m a transmitir uma doutrina gramatical prescritivo-normativa, com ênfase na memorização da nomenclatura gramatical e na prática de análises sintáticas e morfológicas de frases descontextualizadas, tratando o português vivo como uma língua morta, as novas concepçóes de ensino de língua materna propóem como seu objeto a língua em uso, a partir de textos autênticos (falados e escritos), consubstanciados nos múltiplos gêneros textuais que circulam na sociedade. A descrição gramatical, se julgada necessária e pertinente em determinado momento do percurso pedagógico, deve ser um processo de construção dos conhecimentos linguísticos, segundo o trajeto uso $\rightarrow$ reflexão $\rightarrow$ uso, e não de mera transmissão-memorização de nomenclatura. Nesse contexto, as atividades epilinguísticas desempenham um papel muito mais importante e produtivo do que as metalinguisticas, que devem se subordinar àquelas.

Os LD constituem, em muitos ambientes escolares, sobretudo no universo do ensino público brasileiro, a principal (quando não única) ferramenta para o processo de letramento não só dos alunos (e, muitas vezes, de sua família) como também dos próprios docentes, cuja formação é reconhecidamente precária. Fornecer a esse público discente-docente livros de boa qualidade teórica e metodológica, sintonizados com os avanços das ciências da linguagem e da educação, representa, portanto, uma política de aprimoramento do ensino 
e, consequentemente, de construção da cidadania. A importância dos LD na educação brasileira em geral e na educação em língua materna em particular é claramente demonstrada pelo volume de publicaçôes que, nos últimos anos, vem se acumulando em torno do tema.

Infelizmente, a maioria dos LD, mesmo os aprovados no PNLD, revelam um notável desequilíbrio interno: de um lado, apresentam boas coletâneas de textos para o aprendizado da leitura e interessantes propostas de produção textual, com metodologias adequadas e suporte teórico valioso para o eixo leitural escrita; do outro, porém, ainda se apegam em demasia aos moldes convencionais do "ensino de gramática" centrado quase exclusivamente no desdobramento exaustivo da nomenclatura tradicional e na sua aplicação mecânica à análise de frases artificiais, inautênticas, sem nenhuma especificação do contexto de interação verbal em que se realizam. Muito comum também é a tentativa de preservação de formas linguísticas obsoletas, caídas em desuso há muito tempo, não só na língua falada pelos cidadãos urbanos mais escolarizados, mas igualmente na língua escrita mais monitorada, inclusive nas manifestaçóes literárias dos últimos cem anos. Muitos LD ainda tratam como "formas a evitar" várias opções linguísticas já consagradas há mais de meio século (senão há século e meio) na escrita dos nossos melhores escritores, jornalistas, tradutores e ensaístas, fenômenos morfossintáticos que revelam, simplesmente, que a língua mudou, como é da natureza de toda e qualquer língua humana viva. A maioria dos LD veicula uma "norma padrão" ou "norma culta" (sinonímia equivocada que se estampa em praticamente todas as obras) muito distante da realidade dos usos falados e escritos pelos cidadãos brasileiros que recebem, na pesquisa linguística, o rótulo de cultos. Por conseguinte, tais obras se revelam, lamentavelmente, mais prescritivas e intransigentes do que as gramáticas normativas e os dicionários assinados por nossos filólogos mais conceituados, que já acolhem sem hesitação as formas inovadoras ou, pelo menos, relativizam seus julgamentos acerca delas. É o que tentaremos mostrar.

\section{Corpus e metodologia}

Para este trabalho, analisamos as 24 coleções de LD de Língua Portuguesa, destinados ao segmento da $5^{\mathrm{a}}$ à $8^{\mathrm{a}}$ série, num total, portanto, de 96 volumes, que foram aprovadas para serem adquiridas pelo Ministério da Educação 
dentro do PNLD (Programa Nacional do Livro Didático), em sua edição de 2008, da qual o autor participou ${ }^{1}$.

Como se sabe, após o processo de avaliação e de seleção/exclusão das obras inscritas no programa, o Ministério da Educação (por meio do FNDE) publica um Guia dos Livros Didáticos, destinado a auxiliar os professores no processo de escolha das obras. Cada disciplina do currículo escolar tem seu próprio Guia. Nessa publicaçáo, os professores sáo informados sobre os princípios e critérios aos quais os autores/editores devem se adequar para que suas obras sejam bem avaliadas; têm acesso à Ficha de Avaliação usada pelos pareceristas como principal ferramenta do processo e, principalmente, são apresentados às obras selecionadas através de resenhas que explicitam as principais características da coleção, indicam os pontos fracos e fortes da obra específica e dáo sugestôes para o bom aproveitamento dos LD em sala de aula.

Vale insistir no fato de que todos os LD que serviram de corpus para a nossa pesquisa foram aprovados pelo processo de avaliação do PNLD 2008. Isso significa, desde logo, que são bons, constituem material recomendável para o ensino de Língua Portuguesa nas escolas públicas e apresentam, todos eles, qualidades que justificam sua inclusão no programa de compras do governo. É claro que não existe coleção perfeita, mas as eventuais insuficiências que cada uma delas apresenta são superadas por seus aspectos positivos.

$\mathrm{O}$ que vamos fazer aqui, portanto, nem de longe representa uma contestação dos resultados do processo avaliativo - o que seria incoerente da nossa parte, uma vez que participamos das decisóes finais desse processo como coordenador regional. Nosso foco serão os conhecimentos linguísticos e seu tratamento nas coleçōes aprovadas. Pretendemos mostrar por que esse tratamento, mesmo em coleçôes bem avaliadas, está longe de ser satisfatório numa perspectiva mais sintonizada com as teorias linguísticas contemporâneas e com os objetivos de uma educação em língua materna que favoreça o letramento dos aprendizes.

Esse aspecto insatisfatório é reconhecido, aliás, no próprio Guia de Livros Didáticos PNLD 2008. Fazendo um balanço das opçôes metodológicas

1 Cf. BAGNO, Marcos. Gramática, pra que te quero? Os conbecimentos linguísticos nos livros didáticos de língua portuguesa. Curitiba, Aymará, 2010. 
predominantes em cada coleção no tocante aos diferentes eixos de ensino, os redatores do Guia apontam²:

- Nas atividades de leitura, a maioria das coleções aprovadas $(83,33 \%)$ recorre à perspectiva construtivo-reflexiva. [...]

- Já no que diz respeito às atividades de produção escrita, $75 \%$ das obras aprovadas recorrem ao uso situado. [...]

- No que se refere à reflexão e à análise sobre a língua e a linguagem, e em particular à construção de conhecimentos linguísticos, as obras aprovadas no PNLD/2008 ainda recorrem majoritariamente à tradicional abordagem transmissiva, presente em 18 coleçóes $(75 \%)$. Em seis delas (25\%), esta é a metodologia visivelmente privilegiada, o trabalho com conhecimentos linguísticos pouco ou nada se distanciando do tradicional, principalmente no que diz respeito aos tópicos de gramática. [...]

Existe, portanto, um notável desequilibrio metodológico interno no conjunto das coleçóes aprovadas pelo PNLD 2008. Enquanto para leitura e escrita as obras recorrem, em sua maioria, a metodologias consideradas mais sintonizadas com o estado atual da pedagogia de língua materna ${ }^{3}$ - a construção-reflexão e o uso situado -, quando se trata dos conhecimentos linguisticos ainda impera uma perspectiva de ensino conservadora.

Como demonstraçóes desses problemas teórico-metodológicos, apresentaremos a seguir a abordagem oferecida pelos LD analisados a 3 fenômenos linguísticos:

\section{1. o fonema;}

2. os demonstrativos;

\section{3. as regências verbais.}

2 BRASIL. Guia do livro didático. Língua Portuguesa. 5 a à 8 a séries. Brasília, Ministério da Educação, 2008, p. 21-22.

3 Sobre as definiçốes das metodologias de ensino usadas no processo de avaliação do PNLD (construção-reflexão, uso situado, vivência e transmissão), ver o Guia PNLD 2008, p. 29-30. 
O tratamento dado pelos LD a esses aspectos da gramática será contrastado com a abordagem oferecida por gramáticas normativas e dicionários de referência ou por outras obras do mesmo gênero, porém embasadas em teorias linguísticas contemporâneas. O que emerge, conforme se verá, é um hipernormativismo da parte dos autores dos LD, mais estrito e estreito do que as prescrições da tradição normativa, na qual, contudo, eles afirmam se inspirar. Daí o nosso título: "Mais realistas do que o rei".

\section{O fonema}

A noção de fonema aparece em 12 das coleçôes analisadas, ou seja, na metade da nossa amostra. A intenção (sempre louvável) é levar os aprendizes a não confundir a letra, o sinal gráfico, com o som da lingua que ela tenta representar. Apesar da boa intenção, a abordagem do conceito de fonema ali é problemática. Primeiro, porque é difícil defender a suposta necessidade de, nessa fase da escolarização, despejar sobre os aprendizes a terminologia técnica da linguística científica ou, pior, da gramática normativa. Observe-se, abaixo, que quase todas as apresentaçóes do conceito de fonema aparecem nos livros da $5^{\mathrm{a}}$ série. Crianças que mal sabem ler e escrever não podem ser submetidas a uma teorização complexa que exige alto poder de abstração. Em seguida, porque, invariavelmente, a noção de fonema que esses livros apresentam está errada. Vamos ver porquêt

1) A unidade sonora mais simples da língua recebe o nome de fonema. (PRA, 5: 39)

2) Assim dizemos que as palavras da língua são compostas de fonemas (sons) e letras. (TUD, 5: 234)

3) As unidades sonoras que diferenciam as palavras buá, bué, buí, buó, buu recebem o nome de fonemas. Os fonemas, vocálicos, semivocálicos ou consonantais, são representados na escrita pelas letras. (LPG, 5: 39)

4 Os livros didáticos serão citados conforme uma sigla de 3 letras. O primeiro número se refere ao volume (5 para a $5^{\text {a }}$ série etc.), seguido da página onde se acha o trecho citado. As referências completas das obras aparecem no final do artigo. 
4) Quando falamos, emitimos unidades mínimas de sons, suficientes para estabelecer distinção de sentido entre palavras. Exemplo: os fonemas $/ \mathrm{n} /$ e $/ \mathrm{m} /$ fazem a diferença entre dizer Ana e ama. Quando escrevemos, buscamos representar os sons com os símbolos combinados para essa representação: as letras.” (oup, 5: 23)

5) Fonema é a menor unidade sonora que se pode isolar em uma língua. Os fonemas têm a propriedade de distinguir as palavras de uma língua. (РPт, 5: 42)

6) O som que estabelece uma diferença significativa entre duas palavras de uma língua chama-se fonema. (TEC, 7: 137)

7) Fonema é a menor unidade sonora de uma palavra falada." (PLI, 5: 52)

8) Os sons característicos de uma determinada língua são chamados fonemas. A representação escrita desses sons é chamada de letra. (IDE, 5: 25)

9) Todo som capaz de diferenciar, na língua falada, uma palavra da outra chama-se fonema (do grego phone, 'som'). Na língua escrita os fonemas são representados pelas letras. (TXL, 5: 154)

10) Ao refletir e realizar algumas atividades nas páginas anteriores, você pôde perceber que nem sempre há a correspondência entre som (fonema) e letra [...]. O fato de nem sempre haver correspondência entre som e letra gera dúvidas quanto à ortografia de certas palavras. (TCL, 5: 165)

11) Fonemas são os sons da fala. (LNO, 6: 34)

12) Os fonemas são os sons que têm significado para os falantes da língua. (LNO, 8: 21)

13) Denominamos fonemas aos sons representados pelas letras. (PNL, 5: 20)

14) Fonemas são os sons que usamos na língua que falamos, para estabelecer diferenças de significado entre as palavras. (LDM, 6: 135)

15) Na língua oral, a menor unidade é o fonema. [...] Quando falamos, usamos fonemas. (LDM, 8: 17) 
Em todas essas definiçóes de fonema ocorre um equívoco fundamental: o de designar o fonema como "som da língua". Se é verdade que na palavra fonema está presente o elemento de origem grega fone-, derivado de phoné, que realmente significa "som", nela também está presente o elemento -ema, igualmente grego, empregado na teoria linguística para a formação de conceitos abstratos como sistema, morfema, semema, semantema, lexema etc. Isso já serve de sinal de alerta: o fonema é uma entidade virtual, abstrata, jamais um "som da língua".

Numa consulta ao dicionário Houaiss, a primeira acepção de fonema realmente é: "unidade sonora da fala; som da fala" - no entanto, essa acepção vem encabeçada pela seguinte marca: "Diacronismo: obsoleto". De fato, a definição de fonema como um "som da fala" foi abandonada pelos estudiosos da linguagem há mais de cem anos:

O linguista polonês Jan Baudouin de Courtenay, que desde 1870 tinha insistido na divisão entre fonema e som, definiu o fonema em termos estritamente psicológicos. Para ele, o fonema era o equivalente psíquico do som cujo estudo ficaria por conta da psicofonética. Sapir (1944), linguista norte-americano, enfatizou, também, o valor psicológico do sistema fonológico de uma língua. Para Sapir, os fonemas seriam sons ideais que os falantes intentam produzir e os ouvintes creem escutar. ${ }^{5}$

Os livros didáticos que definem fonema como "som da língua" estão, por conseguinte, teoricamente atrasadíssimos (algo como 130 anos).

Se um fonema não é um "som da língua", o que é, então? Voltando ao Houaiss, lá encontramos, como segunda acepção:

unidade mínima das línguas naturais no nível fonêmico, com valor distintivo (distingue morfemas ou palavras com significados diferentes), porém ele próprio não possui significado [...]

5 CORBERA MORI, Ángel. "Fonologia”, in Mussalim, F.; Bentes, A. C. (orgs.), Introdução à linguística, vol. 1. São Paulo, Cortez, 2001, p. 152. 
A linguística estrutural, inagurada por Saussure, distingue dois ramos de estudo: a fonética e a fonologia (também chamada fonêmica). A fonética está no plano da fala concreta - que Saussure chamava de parole -, empiricamente coletável, captável por nossos ouvidos; isto é, a fonética estuda os sons da lingua, que podemos, por exemplo, gravar (antigamente em fita, hoje em mídias digitais) e analisar em aparelhos cada vez mais sofisticados. A fonologia, por seu turno, se situa no plano do sistema - que Saussure chamava de langue -, sistema que não está ao nosso alcance empírico direto, sendo, portanto, um construto teórico, algo que se deduz depois de análises atentas do que ocorre na fala real, concreta. O sistema é, portanto, uma abstração. E é bem no nível do sistema que se situa o fonema. Donde se conclui que o fonema é também uma abstração. Daí ser impossível fazer o que alguns livros pedem: "pronunciar" ou "articular" fonemas - como pronunciar uma abstração teórica?

Outro problema no uso da noção de fonema está no fato dela já ter sido praticamente abandonada nos estudos científicos contemporâneos:

Desde 1950, mais ou menos, se sabe que há vários problemas com o conceito de fonema. Em alguns dialetos do inglês americano, por exemplo, a distinção fonêmica entre /I / e $/ \varepsilon /$ (p. ex. cf. pit/pet) é neutralizada diante de uma nasal, de modo que pin e pen ou Jim e gem são homófonas. A vogal que ocorre nessas palavras, aproximadamente um $[\widetilde{\varepsilon}]$, deve ser um alofone de /I / ou / $\varepsilon /$, porque ela se acha em distribuição complementar com ambas - mas é um alofone de qual das duas? A fonologia gerativa considera esse e outros paradoxos como argumento definitivo contra o postulado de um nível fonêmico de representaçáo. Esses argumentos contra o fonema foram amplamente aceitos, levando a uma rejeição quase universal do fonema como um elemento da teoria linguística ${ }^{6}$.

6 International Encyclopedia of Linguistics. 2nd edition. Oxford, Oxford University Press, 2003, verbete phoneme, tradução nossa. 
É um equívoco teórico, portanto, dizer que fonema é "som". Mas seria entâo o caso de apresentar aos alunos o conceito estruturalista clássico de fonema? Ora, esse conceito exige uma capacidade de abstração teórica que não se pode exigir de crianças (nem de adultos) nessa fase de escolarização. A grande maioria dos estudantes de Letras se forma sem conseguir explicar a contento o que é um fonema, numa perspectiva teórica mais rigorosa. Além do mais, para que recorrer, no ensino fundamental, a uma noção que já foi abandonada pela teoria linguística?

O que importa é levar os aprendizes a se conscientizar de que não existe correlação exata entre o que se fala e o que se escreve, entre letra e som. Assim procede a coleçáo PRL:

16) As letras do alfabeto representam os sons da língua, mas você vai ver que não há uma correspondência perfeita entre letras e sons. (PRL, 5:250)

Como se vê, para tratar dessa não-correspondência perfeita não é preciso recorrer à terminologia científica, ainda mais se for para usá-la de maneira errada, obsoleta, como se fazia antes do final do século XIX.

\section{Os demonstrativos}

O emprego dos demonstrativos no português brasileiro (doravante $\mathrm{PB}$ ) nem de longe corresponde às regras estritas que os LD analisados tentam ensinar a seus usuários. Como vamos ver, mesmo nas gramáticas normativas se reconhece que na língua viva, inclusive na escrita literária, a situação é bem outra.

O português clássico (ou seja, aquele que não é falado nem escrito no Brasil) apresenta uma divisão tripartite dos demonstrativos, cada um deles referente a uma das pessoas do discurso:

\begin{tabular}{|l|l|}
\hline PESSOA & DEMONSTRATIVO \\
\hline $1^{\mathrm{a}}$ & este(s) / esta(s) / isto \\
\hline $2^{\mathrm{a}}$ & esse(s) / essa(s) / isso \\
\hline $3^{\mathrm{a}}$ & aquele(s) / aquela(s) / aquilo \\
\hline
\end{tabular}


O quadro clássico dos demonstrativos - junto com exercícios que tentam apresentá-lo como a única possibilidade aceitável de emprego desses determinantes (que a nomenclatura oficial chama, erradamente, de "pronomes") - vem estampado em 17 das 24 coleçôes analisadas, ou seja, 80.7\% delas.

Sobre o emprego dos demonstrativos em português, os gramáticos coincidem em grandes linhas, inclusive no que diz respeito à não-obediência estrita do vínculo entre pessoa do discurso e pronome:

Pronomes demonstrativos - São os que indicam a posição dos seres em relação às três pessoas do discurso. [...] Nem sempre se usam com este rigor gramatical os pronomes demonstrativos; muitas vezes interferem situaçôes especiais que escapam à disciplina da gramática.[...]

Estas expressôes não se separam por linhas rigorosas de demarcação; por isso exemplos há de bons escritores que contrariam os princípios aqui examinados e não faltam mesmo certas orientaçóes momentâneas do escritor que fogem às perscrutações do gramático ${ }^{7}$.

Estas distinçôes que nos oferece o sistema ternário dos demonstrativos em português não são, porém, rigorosamente obedecidas na prática ${ }^{8}$.

Pronomes demonstrativos são palavras que assinalam a posição dos objetos designados, relativamente às pessoas do discurso. [...] Esta é a norma geral. Veremos, mais tarde, que nem sempre os demonstrativos se usam com essa rigidez. [...] Não há, entretanto, muito rigor na distinção de isto e isso, em virtude da predominância dos seus valores estilísticos sobre os seus valores gramaticais?.

7 BECHARA, Evanildo. Moderna gramática portuguesa. 39ª ed., Rio de Janeiro, YHL, 1999, p. $167 ; 188$.

8 CUNHA, Celso; CINTRA, L. F. Lindley. Nova gramática do português contemporâneo. Rio de Janeiro, Nova Fronteira, 1985, p. 322.

9 ROCHA LIMA, L. H. Gramática normativa do português. $30^{\mathrm{a}}$ ed., Rio de Janeiro, José Olympio, 1989, p. 101; 294. 
Como se depreende dos trechos citados, e lembrando que os gramáticos têm como seu objeto exclusivo de estudo a língua literária consagrada, o emprego dos demonstrativos, já nessa modalidade, escapa à correspondência estrita com as pessoas do discurso e depende, bem mais, das relaçóes afetivas de proximidade ou distância que o escritor estabelece com o objeto, o tempo, o lugar e o evento discursivo designados.

Se assim se manifestam os gramáticos, é antipedagógico o procedimento dos LD analisados de propor exercícios que cobram o uso "adequado" dos demonstrativos, fazendo referência a uma fictícia "variedade padrão" que não corresponde nem sequer à escrita literária clássica, como testemunham os exemplos citados nas gramáticas normativas. Vejamos:

17) 1. Empregue adequadamente pronomes demonstrativos nas frases:

a) $\square$ lápis aqui estão sem ponta. Não posso usá-los.

b) $\square$ pontos no céu parecem estrelas, mas infelizmente são balóes.

c) Adoro $\square$ teus olhos sorridentes.

d) O que é $\square$ que você escondeu?

e) $\square$ é o dia mais feliz de minha vida.

f) Náo encontrei $\square$ livros que você pediu. Entáo trouxe $\square$ aqui.

2. Leia esta tira, de Fernando Gonsales.

[...]

a) A que se refere o pronome isso?

b) Se o objeto a que o pronome se refere está próximo de quem fala, qual seria a forma adequada, de acordo com a variedade padrão?” (PLI, 5: 193)

A impropriedade do exercício se torna ainda mais evidente quando se percebe, na primeira atividade, que todas as frases (nada autênticas) estấo expressas na $1^{a}$ pessoa do singular, ou seja, tentam reproduzir situaçóes de língua falada espontânea, modalidade em que a distinção estelesse já deixou de existir há muito tempo, no que foi acompanhada - como explicam as gramáticas normativas - pela escrita literária. O mesmo vale para a segunda atividade, que reproduz uma tira humorística, em que os personagens falam, dialogam entre si. 
Uma única coleção faz alguma referência à indistinção entre este e esse:

18) $\mathrm{Na}$ linguagem falada do dia-a-dia normalmente não nos preocupamos com a diferença entre esta e essa, porque a diferença de sentido entre elas fica clara pela situação. Entretanto, se a intenção for empregar as palavras com precisão, em uma frase como a da ilustração da atividade 2 , o pronome esta é mais adequado porque dá a ideia de tempo presente. (LEC, 5: 113)

Apesar dessa tentativa de apresentação da língua real, há equívocos evidentes nela. A frase a que se referem as autoras é de uma ilustração, produzida especialmente para o LD, em que a máe pergunta à filha, deitada na cama: "Como se sente esta manhă, querida?", ao que a menina responde: "Não muito bem, acho que não poderei ir à escola" - frases, como se vê, de um evidente artificialismo (que adolescente brasileira diz "não poderei ir à escola"?). Ora, não existe necessidade alguma de "precisão" nesse diálogo: não há possibilidade da menina ter dúvidas sobre a que "manhâ" a mãe se refere, de modo que o uso de essa estaria perfeitamente adequado (e mais condizente com o PB atual). Além disso, como é o procedimento habitual dos LD de metodologia transmissiva, a rápida menção do que se passa na realidade de usos da língua é logo suplantada por exercícios que pedem ao aluno que empregue, tal como na coleção PLI, o pronome demonstrativo "adequado" para preencher frases supostamente enunciadas em $1^{a}$ pessoa e que, só por isso, dispensariam a tal "precisão" (que, insistimos, nem mesmo na linguagem literária mais consagrada é observada). No volume da $6^{a}$ série (p. 76) de LEC, o quadro clássico é retomado, agora sem nenhuma referência à indistinção no emprego dos pronomes e com exercícios do mesmo tipo, com frases também em $1^{a}$ pessoa.

Mais inadequado ainda é o exercício proposto pela coleção TCL (5: 193), em que se pede aos alunos que preencham espaços vagos com demonstrativos, sem que se tenha feito qualquer apresentação prévia desses pronomes, nem sequer em sua distribuição clássica.

Se já na língua literária os gramáticos reconhecem a impossibilidade de normatizar rigidamente o emprego dos demonstrativos, não há por que exigir dos falantes comuns que continuem a usar, tanto na fala quanto na escrita, o pronome este, que cada vez mais se transforma num fóssil lin- 
guístico, isto é, num elemento gramatical que vai ficando restrito a poucas modalidades de uso da língua, como os textos escritos mais monitorados. E nunca é demais repetir: ninguém está propondo que nossos alunos não tenham acesso ao conhecimento do quadro clássico dos demonstrativos, mas simplesmente que esse quadro seja devidamente criticado pela comparação com o que realmente acontece na língua (recorrendo-se, até mesmo, às gramáticas normativas).

\section{Regências verbais}

Os autores dos LD que tratam os conhecimentos linguísticos na perspectiva transmissiva parecem desejar que suas obras sirvam como "minigramáticas" e, para isso, distribuem, ao longo dos 4 volumes que formam a coleção, todo o conteúdo tradicional dos compêndios normativos e na mesma sequência - algumas coleçóes, aliás, trazem "apêndices gramaticais” no final de cada volume, nos quais toda a complexa doutrina tradicional é condensada em fórmulas breves e dogmáticas.

Esse desejo fica ainda mais evidente nas 18 coleçóes ( $75 \%$ da amostra) que se ocupam da regência verbal. É sempre no volume destinado à $8^{a}$ série que elas se dedicam ao assunto (as exceçóes são IDE, que faz isso no volume da $7^{\mathrm{a}}$, e LSX, que traz as regências num apêndice gramatical que se repete em todos os volumes).

Por que tratar da regência na $8^{a}$ série? Simplesmente porque é sempre perto do final de seus compêndios normativos que os gramáticos trazem suas listas de regências verbais que podem suscitar "dúvidas". Nenhuma razão de ordem pedagógica, metodológica, cognitiva: somente a pura e simples subserviência à sequenciação dos conteúdos gramaticais que se repete há séculos nos tratados normativos.

Além disso, todas essas coleçôes apresentam as regências verbais mais conservadoras, negando-se a apresentar aquelas que já se incorporaram no uso normal do PB culto contemporâneo e na literatura dos últimos 150 anos. Quando se permitem mencionar regências não tradicionais, a culpa do surgimento dessas é sempre lançada sobre a "informalidade", um rótulo sob o qual são lançados todos os fenômenos de variação e mudança linguísticas que os LD eventualmente mencionam. 
Vale a pena repetir: temos de apresentar, sim, aos alunos as regências tradicionais mas, também - e sem recorrer à falácia da "informalidade" - as regências variáveis, inovadoras, nas quais topamos diariamente, inclusive em textos escritos que nada têm de "informais".

Também nesse tópico, e também sem surpresas, um confronto entre as liçóes dos LD e o que dizem os dicionaristas, os gramáticos e os linguistas revela a estreiteza de horizontes das coleçóes de perfil transmissivo, que deveriam servir de bom instrumental didático para que seus usuários tomassem conhecimento da dinâmica de sua língua materna.

A lista dos verbos que são alvo das prescrições hipernormativas dos LD revela também uma falta de originalidade a toda prova. Muitos outros verbos apresentam hoje em dia regências variáveis, em que uma construção inovadora começa a ganhar terreno (inclusive na escrita monitorada), como é o caso de buscar, cada vez mais construído com a preposição por e não mais como transitivo direto, como descrevem os dicionários ("uma escavadeira blindada que buscava por túneis de contrabando", exemplo colhido na internet); ou do verbo permitir, que se usa muito frequentemente como transitivo direto ("Ele consegue falar pelo celular através do sistema de videoconferência, que o permite conversar em tempo real pelo aparelho", na internet); ou ainda de evitar, que, de transitivo direto ("evitei sair"), se usa cada vez mais como transitivo indireto ("esta gestão evitou de se pronunciar sobre temas debatidos pelas chapas concorrentes”, idem). Mas os LD não se preocupam em registrá-los (nem em condená-los) e se limitam a uma relação de verbos que se repete ad nauseam nos tratados normativos há décadas. O simples fato de serem sempre os mesmos verbos é sinal nítido de que a coerção normativa não produz os efeitos desejados: se produzisse, não estaríamos lendo há cinquenta, sessenta anos as mesmas listas de regências. E também revela que não adianta lutar contra a mudança linguística depois que ela já se completou e as formas novas se instalaram plenamente no sistema gramatical do idioma materno de todo um povo.

No total, são 49 verbos, muitos dos quais aparecem em uma única coleção e são incluídos nas listas por mera idiossincrasia dos autores dos LD (admirar, pisar, visitar, estimar...). A coleção que mais apresenta regências verbais é LEC (20 ao todo). O campeão de preferências é o previsível e enxovalhado verbo assistir, cuja regência transitiva direta para o sentido de "presenciar" ("assisti o filme") continua sendo alvo da campanha persecutória da irracionalidade 
purista - a regência transitiva indireta ("assistir ao filme”) é a única oferecida em todos os 18 livros. Os 16 verbos que aparecem em todas as coleções são:

$\begin{array}{llll}\text { 1. antipatizar } & \text { 5. desobedecer } & \text { 9. namorar } & \text { 13. preferir } \\ \text { 2. aspirar } & \text { 6. esquecer } & \text { 10. obedecer } & \text { 14. querer } \\ \text { 3. assistir } & \text { 7. ir } & \text { 11. pagar } & \text { 15. simpatizar } \\ \text { 4. chegar } & \text { 8. lembrar } & \text { 12. perdoar } & \text { 16. visar }\end{array}$

Qualquer descrição das fases históricas da língua deixa claro que, ao longo do tempo, inúmeros verbos sofreram mudanças em suas regências ${ }^{10}$. Da mesma maneira que ocorreram mudanças de regência do passado para cá, também estão ocorrendo, nesse exato momento, mudanças de regência que, muito provavelmente, vão se cristalizar na língua e serão as únicas consideradas aceitáveis daqui a algum tempo. E essas mudanças se verificam precisamente nos verbos que os LD listam, náo para reconhecer e discutir serenamente essas transformaçôes, mas para condená-las de forma sumária ou, o que é igualmente prejudicial ao ensino, para atribuí-las a uma fictícia "informalidade" ou a um "uso popular":

19) Desde já, chama-se a atenção para o fato de que a regência (ou seja, o fato de um verbo exigir preposição) de alguns verbos varia de acordo com o grau de formalidade do texto. Por isso, a linguagem mais informal pode apresentar diferença da linguagem padrão em relação à regência verbal. (MDC, 8: 15) $\rightarrow$ perceba-se a definição equivocada de regência como "o fato de um verbo exigir preposição", como se a transitividade direta não fosse uma "regência".

20) Muitas vezes, há divergências entre o uso popular e o culto da regência verbal. (MDC, 8: 142)

Como rápida exemplificação da atitude hipernormativa dos autores dos LD analisados, vejamos uma comparação entre o que se encontra nas obras didáticas e o que dizem dicionaristas e gramáticos profissionais, em obras datadas de há pelo menos vinte anos:

10 Cf. BAGNO, Marcos. Gramática pedagógica do português brasileiro. São Paulo, Parábola, 2012, p. 520. 
21) Namorar. VTD - NÃO admite de forma alguma a preposição com. "Luísa namora João há oito anos". (TEC, 8: 231)

21a) “[...] 'Por que você não pode namorar com americanos?' (Carlos Castelo Branco, Continhos Brasileiros, p. 28). [O uso de namorar com esta regência é perfeitamente legítimo, moldado em casar com e noivar com.]". (Novo Dicionário Aurélio da Lingua Portuguesa, verbete namorar)

22) Os verbos transitivos diretos não admitem voz passiva. Assim, não são recomendados pela variedade padrão frases como: As leis não foram obedecidas. (PRA, 8: 190). $\rightarrow$ Em anotação marginal somente para o professor, os autores "explicam": "Observar que, mesmo que a frase pareça correta - pois é frequente -, esse desvio corresponderia a dizer, por exemplo, Esse dinheiro não foi precisado por mim, no sentido de "eu não precisei desse dinheiro".

22a) [obedecer] Admite, no entanto, voz PAssiva: 'Sofreste tanto que até perdeste a consciência do teu império; estás pronta a obedecer; admiras-te de seres obedecida.' (Machado de Assis, OC, III, 1044.) 'Depois de outras muitas e reiteradas ordens foi enfim obedecida.' (M. Barreto, CP, 303.) ${ }^{11}$

É uma lástima concluir que nem sequer a verdadeira tradição normativa rege os livros didáticos de perfil transmissivo...

\section{Por uma educação linguística honesta}

Num importante livro publicado em 2008, Carlos Alberto Faraco ${ }^{12}$ faz um exame sereno e minucioso das questóes sociológicas e pedagógicas implicadas nos discursos sobre norma linguistica que se constituíram ao longo da nossa história. Em dado momento de sua explanação, o autor faz uso da ex-

11 CUNHA; CINTRA, op. cit., p. 520.

12 FARACO, Carlos A. Norma culta brasileira: desatando alguns nós. São Paulo, Parábola, 2008. 
pressão norma curta para se referir ao conjunto de regras hiperprescritivas que algumas pessoas - sobretudo nos meios de comunicação - tentam impor como as únicas válidas. A atitude ali é a do purismo extremado, que se recusa a reconhecer a mudança linguística em geral, que não aceita nem mesmo as inovaçôes morfossintáticas empregadas há século e meio por escritores consagrados e já contempladas sem escândalo naquilo que Faraco chama de "bons instrumentos normativos" (compêndios gramaticais e dicionários produzidos por filólogos e linguistas bem conceituados).

Não é motivo de alegria constatar, ao final da nossa análise do tratamento dado aos conhecimentos linguísticos nas coleçóes de LD aprovados pelo PNLD 2008, que na maioria delas também impera essa norma curta. Ela acaba sendo validada pelos LD sobretudo quando recorrem à "informalidade" como rótulo para qualificar as inovaçóes que, pelo processo ininterrupto da mudança linguística, se fixaram como regras gramaticais do português brasileiro, inclusive em suas modalidades faladas e escritas mais formais, mais monitoradas.

Nos parece muito grave, por ser consciente, o procedimento adotado em algumas coleções de apresentar, no livro destinado ao aluno, a prescrição de formas linguísticas caídas em desuso há muito tempo e, junto com ela, em anotaçóes dirigidas apenas ao professor, observações pertinentes sobre a realidade dos usos da língua, observaçóes que deveriam estar estampadas também - senão principalmente - no livro do aluno. Com isso, tenta se ocultar dos aprendizes a realidade variável e mutante de sua língua, ao mesmo tempo em que se procura apresentar essa língua (mesmo que seja em sua "variedade culta”) como um sistema estável e homogêneo.

O caso mais eloquente é o da coleção PRA, que usamos aqui como exemplo dessa duplicidade de tratamento dos conhecimentos linguísticos. As citaçóes abaixo são observaçóes marginais, em corpo menor e impressas em outra cor, coletadas dos exemplares destinados ao professor:

23) No uso diário, praticamente desapareceu a diferença entre esse e este (6: 63) $\rightarrow$ apesar disso, no livro do aluno, a coleção exibe o quadro tradicional dos demonstrativos, tentando relacionar as formas este / esse I aquele com as pessoas do discurso... 
24) Professor: a questão do se - índice de indeterminação do sujeito - ou se - pronome apassivador - é das mais complicadas na nossa gramática. A tendência é, na língua falada, entender como frases com sujeito indeterminado as frases na passiva sintética, fazendo esta concordância não prescrita pela norma culta: vende-se casas, conserta-se joias etc. $(6: 258)$

25) [...] Dificilmente encontraremos uma explicação lógica que os convença [os alunos] de que o sujeito em Precisa-se de um apartamento de dois quartos é indeterminado e em Procura-se um apartamento de dois quartos, não. (7:76) $\rightarrow$ por que, então, não apresentar aos alunos a ilogicidade da regra normativa em vez de continuar a transmiti-la sem comentários?

26) A questão da colocação pronominal é uma das que mais provocam discussóes a respeito da variedade padrão. $\mathrm{O}$ uso vem sacramentando, cada vez mais, opçóes não recomendadas pela variedade padrão. As divergências decorrem principalmente pelas [sic] variações no modo de falar entre brasileiros e portugueses. Estes usam, com muito mais naturalidade, a ênclise e a mesóclise, pois o pronome oblíquo para eles é realmente átono. No Brasil, a próclise tem a preferência geral, pois o pronome oblíquo para nós é realizado como tônico, e não átono [...]. (8: 114) $\rightarrow$ por que, então, no livro do aluno, gastar tantas páginas com as regras e subregras obsoletas de colocação pronominal que nada têm que ver com o português brasileiro?

Observaçôes que poderiam levar os alunos a ter uma visão dinâmica de sua língua são sonegadas a eles, por causa do compromisso ideológico tão presente na maioria dos LD de apresentar uma língua "culta" homogênea e estável, uma norma curta.

É de admirar que nos mesmos LD que apresentam excelentes discussóes sobre temas relevantes da vida atual - defesa do meio ambiente, diversidade étnica e cultural, publicidade e consumismo, trabalho infantil, drogas, violência urbana, direitos das minorias etc. - também encontremos, nas seçóes destinadas ao ensino da língua, essa ideologia absolutamente arcaica, em franca contradição com a realidade do mundo contemporâneo. 
Faz parte da educação linguística levar o aprendiz a entrar em contato - também - com a norma-padrão tradicional. Apresentar as regras padronizadas, normatizadas, sobretudo para o entendimento dos conflitos existentes entre o que é norma culta (real) e o que é norma-padrão (ideal), é pedagogicamente pertinente. No entanto, não se pode fazer essa apresentação sob alegaçôes falsas - "esse é o modo mais valorizado, mais prestigiado de falar a língua", por exemplo, ou atribuir à "informalidade"/“oralidade"/“coloquialidade" construçóes gramaticais amplamente encontráveis em textos escritos formais.

Uma abordagem adequada mostraria, ao lado das regras normatizadas, obsoletas, os usos reais da língua, encontrados nos textos autênticos que, por exemplo, os próprios LD oferecem para o trabalho com a leitura e a produção textual. A escuta atenta de falas autênticas - como entrevistas com falantes "cultos" no rádio ou na televisão - também permitiria reconhecer o que são e como são as verdadeiras normas urbanas de prestígio. Falas autênticas também seriam bem-vindas para um contato mais realista com as variedades estigmatizadas, no lugar das tirinhas do Chico Bento e outras manifestações artísticas.

Ao invés de propor análises equivocadas, como vimos acima, é possível sugerir atividades de comparação e contraste entre o que prescreve a norma-padrão e o que de fato se verifica na norma culta. Toda manifestação linguística é inevitavelmente hibrida e, assim, seria de grande valor pedagógico (e para a formação cidadã) incentivar a observação da ocorrência, num mesmo texto falado ou escrito altamente monitorado, de regras normatizadas e de regras não-normatizadas, mas já incorporadas à gramática real do $\mathrm{PB}$ - sem propor aos alunos, evidentemente, "corrigir" ou "passar para a norma culta" essas ocorrências que fogem do padrão tradicional.

Para tanto, é claro, precisamos de docentes com sólida formação científica e prática de pesquisa - o que, infelizmente, ainda está muito longe de ser o habitual. Apesar disso, na medida em que os LD constituem, como sabemos, o instrumental pedagógico preferencial (para não citar os ambientes em que é o único), as autoras e os autores desses livros, que tiveram o privilégio de receber uma boa formação cientifica em universidades de justificado renome $e^{13}$, poderiam

13 Metade dos autores e autoras dos livros didáticos analisados nesta pesquisa, por exemplo, fizeram sua formação na Universidade de São Paulo (USP), considerada há décadas a melhor da América Latina. Nada justifica, portanto, seu desprezo a uma abordagem dos conhecimentos linguísticos mais sintonizada com os avanços das ciências da linguagem e da educação. 
se engajar na produção de obras menos comprometidas ideologicamente com a norma curta e mais voltadas para uma verdadeira educação linguistica. Esse engajamento recebe pleno apoio das atuais diretrizes oficiais da educação brasileira - então, por que não fazer dessas coleçôes, já merecidamente aprovadas, obras ainda melhores, dignas de avaliaçóes ainda mais positivas? Se o mercado editorial brasileiro é amplamente dominado pelas aquisiçôes governamentais de material didático, por que não responder integralmente às diretrizes que o governo já traçou no rumo de uma educação cada vez melhor?

Vejamos um exemplo simples e prático do que poderia ser esse trabalho. Diversas coleçóes da nossa amostra tratam da (suposta) diferença entre onde e aonde. No entanto, esse tratamento se faz exclusivamente pela ótica da norma curta, isto é, pela prescrição de regras que não encontram apoio nem mesmo na melhor bibliografia normativa. Vamos ver primeiro o que aparece nas coleçóes:

27) Observe como aonde foi empregado a seguir, depois responda: [...] Onde o termo "aonde" foi empregado adequadamente? Justifique. (TXL, 6: 103)

28) O pronome relativo onde deve ser empregado apenas para indicar um lugar concreto, nunca uma situação [...]. Aonde é usado quando o verbo exige a preposição $a$. (PRA, 7: 314)

29) onde - lugar em que / aonde - para o lugar que, ao lugar que (em direção = "para onde"). (TUD, 8: 237)

30) É preciso não confundir o emprego do pronome relativo onde com aonde. $\mathrm{O}$ primeiro indica permanência em um lugar enquanto o segundo indica movimento para um lugar. (PNL, 8: 53)

31) [Após leitura de um texto de Eduardo Martins sobre a suposta diferença] Aplique o que você aprendeu com a leitura desse texto e reescreva as frases a seguir em seu caderno, substituindo o $\leftarrow$ pelas palavras onde ou aonde. (LPG, 7:283)

32) onde - indica o lugar em que se encontra algo ou alguém. / aonde $(a+$ onde $)$ - equivale a para onde. Emprega-se sempre com verbos que indicam movimento (ir a algum lugar). (IDE, 5: 228) 
Vejamos agora o que dizem dois gramáticos, um dicionarista e uma linguista, todos grandes especialistas nos estudos da língua portuguesa:

33) Embora a ponderável razão de maior clareza idiomática justifique o contraste que a disciplina gramatical procura estabelecer, na língua culta contemporânea, entre onde (= o lugar em que) e aonde (= o lugar a que), cumpre ressaltar que esta distinçáo, praticamente anulada na linguagem coloquial, já não era rigorosa nos clássicos ${ }^{14}$

41) $\mathrm{O}$ uso dos melhores autores [...] desde um Azurara, da fase arcaica da língua, até um José Régio ou um Miguel Torga, dos nossos dias, náo distingue onde de aonde. Clássico dos mais reputados, Rebelo da Silva usa aonde por onde cerca de 40 vezes nos seus Contos e Lendas; uma delas (só para exemplificar), na pág. 20: "o cemitério aonde dormem os que nos amaram." Por vezes ocorre o emprego simultâneo de um e outro advérbio com a mesma significação: "Nise? Nise? onde estás? aonde? aonde?” (Cláudio Manuel da Costa, Obras Poéticas, I, p. 109); "Mas aonde te vais agora, / Onde vais, esposo meu?" (Machado de Assis, Poesias Completas, p. 207). Note-se, na abonação machadiana, que a métrica não se oporia à repetição do aonde $e^{15}$

42) Aonde é a combinação da preposição a com o advérbio ou pronome relativo onde. Em princípio, corresponde, pois, a para onde, indicando direçấo. [...] Essa é a recomendação de uso, atualmente, para a língua culta, embora seja generalizado o uso de aonde por onde, e vice-versa, uso que, aliás, também se verificava em escritores clássicos $^{16}$

Diante dessas análises ponderadas, por que nossos LD ainda se prendem de modo tâo ferrenho à norma curta e não apresentam a seus usuários - docentes e discentes - uma discussão mais viva e interessante do fenômeno estudado?

14 CUNHA; CINTRA, op. cit., p. 342-343.

15 FERREIRA, Aurélio B. H. Novo dicionário Aurélio da língua portuguesa. Curitiba, Positivo, 2012, verbete aonde.

16 NEVES, Maria Helena M. Guia de usos do português. São Paulo, Unesp, 2003, p. 77. 
$\mathrm{Na}$ coleção LPG, no mesmo livro da $7^{\mathrm{a}}$ série em que aparece o texto de Eduardo Martins ${ }^{17}$ sobre a suposta distinção entre onde e aonde, o leitor encontra, poucas páginas adiante, um soneto de José Bonifácio, o Moço (18271886), aonde se lê:

Deserta a casa está... Entrei chorando,

De quarto em quarto, em busca de ilusôes!

Por toda a parte as pálidas visôes!

Por toda parte as lágrimas falando!

Vejo meu pai na sala, caminhando,

Da luz da tarde aos pálidos claróes,

De minha mãe escuta as oraçóes

$\mathrm{Na}$ alcova, aonde ajoelhei rezando.

Brincam minhas irmãs (doce lembrança!...)

Na sala de jantar... Ai! mocidade,

És tão veloz, e o tempo não descansa!

Oh! sonhos, sonhos meus de claridade!

Como é tardia a última esperança!...

Meu Deus, como é tamanha esta saudade!...

(LPG, 7: 303) [sublinhado meu]

Ora, apenas 20 páginas separam o texto normativo-prescritivo de E. Martins e o soneto de Bonifácio. Como fica o aluno (e o professor) diante dessa contradição, presente numa mesma unidade didática? Terá de atribuir o uso de aonde nesse poema - um soneto parnasiano! - à "informalidade”, à "coloquialidade"? É óbvio que não.

Uma educação linguística honesta e comprometida com a boa formação de nossos alunos não pode permitir o falseamento da realidade em nome de

17 Eduardo Martins, jornalista falecido em 2008, é o autor do Manual de redação de O Estado de S. Paulo, que serviu de base para as prescrições do livro didático citado. 
uma norma que não é abonada nem sequer pelos nossos melhores gramáticos e dicionaristas, nem muito menos por nossos melhores escritores. Se é para ensinar alguma norma, vamos deixar de querer ser mais realistas do que o rei e cair de uma vez por todas na real?

\section{RÉSUMÉ}

Malgré les progrès de l'enseignement de la langue maternelle au Brésil ces dernières années, le traitement offert para les manuels didactiques de portugais aux connaissances linguistiques s'attache toujours à une pédagogie de transmission acritique des prescriptions normatives traditionnelles. À partir de l'analyse de 24 collections de ces manuels, nous démontrons l'hypernormativisme de ces ouvrages, plus strict que celui de la tradition normative elle-mêmes.

MOTS-CLÉS: didactique du portugais; manuels scolaires; normativisme.

Recebido em: 19/02/2013 Aprovado em: 12/08/2013 


\section{ANEXO}

Coleções de Língua Portuguesa aprovadas no PNLD 2008

\begin{tabular}{|l|l|l|l|}
\hline SIGLA & \multicolumn{2}{|c}{ TÍTULO } & \multicolumn{1}{c|}{ AUTORIA } \\
\hline CCN & Construindo consciências & Celina Diaféria / Mayra Pinto & Scipione \\
\hline DCT & Dialogando com textos & $\begin{array}{l}\text { Lenira Aparecida Buscato / } \\
\text { Maria Beatriz Marcondes Helene } \\
\text { / Maria Paula Parisi Lauria }\end{array}$ & Positivo \\
\hline IDE & Ideias \& Linguagens & $\begin{array}{l}\text { Dileta Delmanto / } \\
\text { Maria da Conceição Castro }\end{array}$ & Saraiva \\
\hline LDM & Leitura do mundo & $\begin{array}{l}\text { Lúcia Teixeira de Siqueira e Oli- } \\
\text { veira / Norma Discini Campos }\end{array}$ & $\begin{array}{l}\text { Editora do } \\
\text { Brasil }\end{array}$ \\
\hline LEC & Ler, entender, criar & $\begin{array}{l}\text { Maria das Graças Vieira / } \\
\text { Regina Figueiredo }\end{array}$ & Ática \\
\hline LNO & Linguagem nova & $\begin{array}{l}\text { Carlos Emílio Faraco / } \\
\text { Francisco Marto de Moura }\end{array}$ & Ática \\
\hline LPG & $\begin{array}{l}\text { Leitura, produção, gra- } \\
\text { mática }\end{array}$ & Leila Lauar Sarmento & Moderna \\
\hline LSX & Linguagens no Século XXI & Heloísa Harue Takazaki & IBEP \\
\hline MDC & Mosaico do conhecimento & $\begin{array}{l}\text { Giórgia Hellou / Robson Luiz } \\
\text { Trindade da Cruz }\end{array}$ & IBEP \\
\hline NDI & Novo Diálogo & $\begin{array}{l}\text { Eliana Santos Beltrão / } \\
\text { Tereza Gordilho }\end{array}$ & FTD \\
\hline OAL & Olhe a Língua! & $\begin{array}{l}\text { Ana Luiza Marcondes Garcia / } \\
\text { Maria Betânia Amoroso }\end{array}$ & FTD \\
\hline OUP & $\begin{array}{l}\text { Português em outras } \\
\text { palavras }\end{array}$ & $\begin{array}{l}\text { Maria Sílvia Gonçalves / } \\
\text { Rosana Fernandes Calixto Rios }\end{array}$ & Scipione \\
\hline PLG & $\begin{array}{l}\text { Português na ponta da } \\
\text { língua }\end{array}$ & $\begin{array}{l}\text { Lino de Albergaria / } \\
\text { Márcia Fernandes / Rita Espeschit }\end{array}$ & Quinteto \\
\hline PLI & Português Linguagens & $\begin{array}{l}\text { William Roberto Cereja / } \\
\text { Thereza Cochar Magalháes }\end{array}$ & Saraiva \\
\hline PNL & Praticando nossa língua & Cristina Soares de Lara Azeredo & Ática \\
\hline PPT & Português para todos & $\begin{array}{l}\text { Ernani Terra / } \\
\text { Floriana Toscano Cavallete }\end{array}$ & Scipione \\
\hline PRA & Projeto Araribá & Coletiva & Moderna \\
\hline PRL & $\begin{array}{l}\text { Uma proposta para o } \\
\text { letramento }\end{array}$ & Magda Soares & Moderna \\
\hline
\end{tabular}




\begin{tabular}{|l|l|l|l|}
\hline RAL & Rumo ao Letramento & $\begin{array}{l}\text { Ângela Mari Gusso / } \\
\text { Rossana Aparecida Finau }\end{array}$ & Base \\
\hline TCL & $\begin{array}{l}\text { Trabalhando com a } \\
\text { linguagem }\end{array}$ & $\begin{array}{l}\text { Givan Ferreira / } \\
\text { Isabel Cristina Cordeiro / } \\
\text { Maria Aparecida Almeida Kaster / } \\
\text { Mary Marques }\end{array}$ & Quinteto \\
\hline TEC & Tecendo linguagens & $\begin{array}{l}\text { Cícero de Oliveira Silva / Eliza- } \\
\text { beth Gavioli de Oliveira Silva / } \\
\text { Lucy Aparecida Melo Araújo / } \\
\text { Tania Amaral Oliveira }\end{array}$ & IBEP \\
\hline TUD & Tudo é linguagem & $\begin{array}{l}\text { Ana Maria Trinconi Borgatto } \\
\text { / Terezinha Costa Hashimoto } \\
\text { Bertin / Vera Lúcia de Carvalho } \\
\text { Marchezi }\end{array}$ & Ática \\
\hline VPO & Textos \& Linguagens & $\begin{array}{l}\text { Márcia de Benedetto Aguiar } \\
\text { Simóes / Maria Inês Candido } \\
\text { dos Santos }\end{array}$ & Escala \\
Educacional
\end{tabular}

